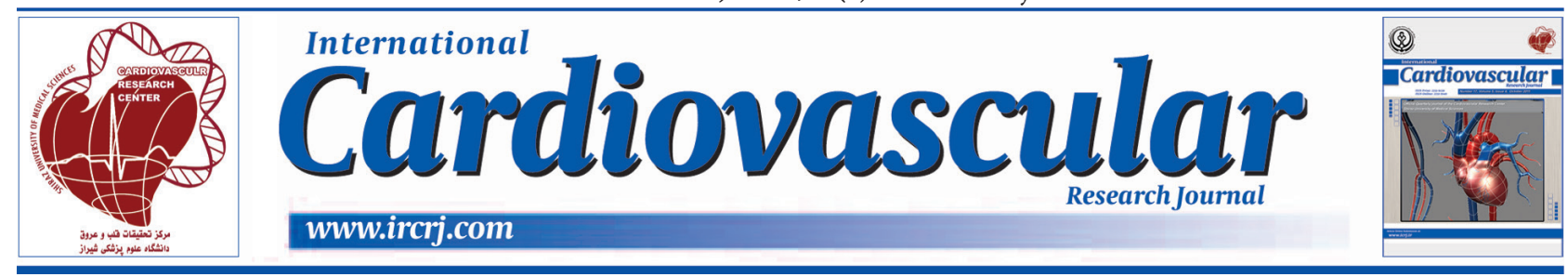

\title{
The Association between PAI-1 Gene Promoter Polymorphism and Serum Serpin E1, MDA, and Hs-CRP Levels in Coronary Artery Disease
}

\author{
Ansar Karimian ${ }^{1,2}$, Safar Farajnia ${ }^{1, *}$, Morteza Ghojazadeh ${ }^{3}$, Fatemeh Khaki-Khatibi 1,4, * \\ ${ }^{1}$ Drug Applied Research Center, Tabriz University of Medical Sciences, Tabriz, IR Iran \\ ${ }^{2}$ Department of Clinical Biochemistry, Faculty of Medicine, Tabriz University of Medical Sciences, Tabriz, IR Iran \\ ${ }^{3}$ Liver and Gastrointestinal Disease Research center, Tabriz University of Medical Sciences, Tabriz IR Iran \\ ${ }^{4}$ Student Research Committee, Tabriz University of Medical Sciences, Tabriz, IR Iran
}

\begin{tabular}{l}
\hline A R T I C L E I N F O \\
Article Type: \\
Research Article \\
\hline Article History: \\
Received: 09 Dec 2015 \\
Revised: 23 Feb 2016 \\
Accepted: 09 Mar 2016 \\
\hline
\end{tabular}

Keywords:

Plasminogen Activator Inhibitor 1

Malondialdehyde

C-Reactive Protein

Coronary Artery Disease

\begin{abstract}
A B S T R A C T
Background: Coronary artery disease (CAD) caused by atherosclerosis. Studies have shown that there are a number of factors which are closely related to the development and progression of CAD that include Cellular binding molecules like Plasminogen Activator Inhibitor-1(PAI-1), Lipid peroxidation, inflammation and hemostasis.

Objectives: The present case-control study aimed to evaluate the association between Plasminogen Activator Inhibitor-1 (PAI-1) 4G/5G polymorphism and oxidative stress markers and Coronary Artery Disease (CAD).

Patients and Methods: Blood was drawn and DNA was extracted from 90 subjects (46 patients with angiographically diagnosed CAD and 44 age- and sex-matched healthy controls). The 4G/5G polymorphism of PAI-1 was detected by Polymerase Chain Reaction-Restriction Fragment Length Polymorphism (PCR-RFLP) analysis. Besides, the risk factors, serpin E1, Malondialdehyde (MDA), high-sensitivity C-Reactive Protein (hs-CRP), and lipid profile serum levels were measured by standard methods and were compared between the two study groups using independent samples t-test, one-way ANOVA, and Mann-Whitney $U$ test as appropriated.

Results: Results: The frequency of $4 \mathrm{G} / 4 \mathrm{G}$ genotype of PAI-1 gene was higher in the CAD patients than in the controls $(28 / 46(60.87 \%)$ vs. $8 / 44(18.18 \%), \mathrm{P}<0.01)$. Additionally, the serpin E1 plasma level was significantly higher in the CAD group carrying the $4 \mathrm{G}$ allele compared to those homozygous for the $5 \mathrm{G}$ allele $(\mathrm{P}=0.016)$. Besides, a significant difference was found between the $4 \mathrm{G} / 4 \mathrm{G}$ and $5 \mathrm{G} / 5 \mathrm{G}$ subjects of the CAD group regarding plasma High-Density Lipoprotein (HDL) $(\mathrm{P}<0.01)$. Also, significant differences were observed among the three genotypes of both groups concerning the plasma levels of cholesterol, triglyceride, and Low-Density Lipoprotein (LDL). However, no significant correlation was found between PAI-1 gene polymorphism and MDA serum level, hs-CRP, and risk of CAD. Conclusion: The findings of this study suggested that 4G/4G PAI-1 polymorphism was associated with cholesterol, triglyceride, LDL, and HDL levels and could be regarded as a biomarker for risk of CAD.
\end{abstract}

Implication for health policy/practice/research/medical education:

Our findings suggested that the $4 \mathrm{G} / 5 \mathrm{G}$ polymorphism of the PAI-1 gene seems to be a useful marker of fibrinolytic activity. Besides, this polymorphism might contribute to defective fibrinolytic activity due to elevated PAI-1 plasma level, eventually increasing the risk of coronary artery disease. Moreover, the study results demonstrated that this genetic variation might be important in correlation with some other factors, such as increased or decreased triglyceride, cholesterol, and LDL and HDL levels. However, no significant correlation was observed between PAI-1 4G/5G gene polymorphism and serum levels of stress oxidative factors, such as MDA and hs-CRP.

*Corresponding author: Safar Farajnia, Drug Applied Research Center, Tabriz University of Medical Sciences, Tabriz, Iran. Tel: +98-9143018589,

E-mail: farajnia@gmail.com.
Fatemeh Khaki-Khatibi, Department of Clinical Biochemistry, Faculty of Medicine, Tabriz University of Medical Sciences, Tabriz, Iran. Tel: +984133364666, Fax: +98-4133364666,

E-mail: fatemehkhakikhatibi@yahoo.com 


\section{Background}

Atherosclerotic Coronary Artery Disease (CAD) remains one of the major health problems around the world. It appears as a multifactorial process caused by interaction of environmental risk factors with multiple predisposing genes. CAD has been ranked as primary cause of mortality and is the major cause of morbidity in the world. It has been estimated that between 1990 and 2020, ischemic heart disease alone will increase by $29 \%$ in men and $48 \%$ in women in developed countries and by $120 \%$ in women and $127 \%$ in men in developing countries (1). Several factors, including blood pressure, high plasma lipids, smoking, diabetes mellitus, and age, are involved in development of $\mathrm{CAD}$ and treatment of these risk factors reduces the rate of mortality (2-4).

Serpin E1, the protein product of Plasminogen Activator Inhibitor-1 (PAI-1) gene, originates from vascular endothelium and platelets. Serpin E1 plays an important role in intravascular thrombosis and high levels of serpin E1 in CAD are associated with the risk of premature atherosclerosis (2). It has also been reported that high levels of serpin E1 are associated with vascular wall impairment and endothelial dysfunction. Moreover, a cross-sectional case-control study indicated that elevated plasma serpin E1 activity was related to intima-media thickness of carotid arteries (4). Human PAI-1 gene is located at chromosome 7q22, and various genetic polymorphisms have been identified in its promoter region (4). A common insertion/deletion of guanine has been detected in this region (2). Deletion of the $4 \mathrm{G}$ allele was associated with increased serpin E1 plasma level due to inability of transcriptional repressor protein for binding to this polymorphic sequence (5). C-Reactive Protein (CRP) is a member of Pentraxin family, which plays a key role in the innate immune response. CRP is the most sensitive acute reactant protein and its concentration increases rapidly during inflammatory processes (6-8). This protein has been shown to have prognostic value in patients with acute coronary syndromes and plays different roles in pathogenesis of atherosclerosis (7).

Malondialdehyde (MDA) is a marker, which is commonly used to evaluate lipid peroxidation. Additionally, its assessment is considered to be an independent marker of oxidative damage. Therefore, MDA could be a useful indicator for identification of patients with CAD (7).

\section{Objectives}

The present study aims to evaluate the association between PAI-1 gene promoter polymorphism and serum serpin E1, MDA, and hs-CRP levels in CAD.

\section{Materials and Methods}

\subsection{Subjects}

The present case-control study was conducted on 90 subjects, including 46 patients with CAD and 44 age- and sex-matched healthy controls. Written informed consents were obtained from all the patients.

CAD was diagnosed based on examination of the results of coronary arteriography ( $>50 \%$ stenosis of at least one major vessel), clinical symptoms, electrocardiogram, echocardiography, and treadmill exercise test. On the other hand, the healthy controls had referred to Tabriz blood transfusion center for voluntary blood donation and none of them reported any past heart problems or family history of CAD. The individuals with the history of heart disease, lung disorder, liver dysfunction, renal disease, and cancer were excluded from the study.

\subsection{Blood Sampling}

Fasting venous blood samples $(10 \mathrm{~mL})$ were collected. The blood samples were centrifuged at $1500 \mathrm{~g}$ at room temperature for 10 minutes and then, the cells and sera were stored at $-70^{\circ} \mathrm{C}$ until analysis.

\subsection{Measurement of Biochemical Parameters}

Serum level of serpin E1 was determined using EnzymeLinked Immunosorbent Assay (ELISA) (eBioscience co. Ltd Cat. No. BMS2033). Besides, MDA serum level was measured based on reaction with Thiobarbituric Acid (TBA) and extraction with normal butanol using the method suggested by Buege and Aust (9). Absorption measurement was also made by a spectrophotometer at $535 \mathrm{~nm}$ and the Optical Density (OD) values were compared to the standard curve. Moreover, serum concentration of hs-CRP was measured by high-sensitivity turbidimetry method using Biosystems kit (Barcelona Spain COD 31927). The assay was analyzed on a semi-auto analyzer (Alcyon 300 made in USA). Lipid profile was also assessed through routine laboratory methods using an automated chemical analyzer. Finally, Low Density Lipoprotein (LDL)-cholesterol level was measured using Friedewald formula (10).

\section{4. $4 G / 5 G$ polymorphism of PAI-1 Gene}

Genomic DNA was extracted from peripheral blood leukocytes with DNG-Plus (Sinaclon, Iran). Then, the common guanosine insertion/deletion polymorphism at position -675 of the PAI-1 gene was determined by Polymerase Chain Reaction (PCR) method. For amplification of the promoter region containing the 4G/5G polymorphism, a couple of primers were designed by Gene Runner software (version 3.05) as follows: 5'CACAGAGAGAGTCTGGCCACGT3' (forward) and 5 'GGCCCAACAGAGGACTCTT3' (reverse). Each DNA amplification was performed in a total volume of $25 \mu \mathrm{L}$ ( $24 \mu \mathrm{L}$ PCR master mix plus, $1 \mu \mathrm{L}$ of template DNA). PCR amplification was carried out in a thermal cycler with the following parameters: initial denaturation at $95^{\circ} \mathrm{C}$ for 4 minutes followed by 35 cycles of denaturation at $94^{\circ} \mathrm{C}$ for 60 seconds, annealing at $62^{\circ} \mathrm{C}$ for 60 seconds, extension at $72^{\circ} \mathrm{C}$ for 30 seconds, with a final extension at $72^{\circ} \mathrm{C}$ for 3 minutes. The PCR products were digested with BesL1 (Thermoscience) at $55^{\circ} \mathrm{C}$ overnight. The digestion products were analyzed by electrophoresis on 3\% agarose gel in a tris-acetat-EDTA (TAE) buffer at 94 volts alongside $50 \mathrm{bp}$ DNA ladder (Fermentas, Lithuania). The gel was finally stained with ethidium bromide and was visualized using the gel documentation system.

\subsection{Statistical Analysis}

Statistical analysis was performed using the SPSS statistical software, version 16. Continuous parameters 
were compared using independent samples t-test, one-way ANOVA, and Mann-Whitney U test where appropriated. On the other hand, the categorical data were expressed as numbers and percentages and were compared using Chisquare test. Independent samples t-test was also used to compare the two groups regarding the study parameters. Finally, Tukey's post-hoc test was used to compare the three genotypes $(4 \mathrm{G} / 4 \mathrm{G}, 4 \mathrm{G} / 5 \mathrm{G}$, and $5 \mathrm{G} / 5 \mathrm{G})$ of PAI-1 gene concerning the study factors. $\mathrm{P}$ values less than 0.05 were considered to be statistically significant.

\section{Results}

The characteristics of the study subjects have been summarized in Table 1. As expected, the established cardiovascular risk factors (e.g., hypertension, diabetes, and smoking) were more prevalent in the CAD group than in the controls. A significant difference was also observed between the two groups with respect to the main factors, including PAI-1, hs-CRP, MDA, and blood sugar level. Lipid-profile analysis also showed a significant difference between the case and control groups concerning LDL, cholesterol, and triglyceride concentrations. In contrast, the concentrations of High Density Lipoprotein (HDL) were lower in the CAD population than in the controls.

Distributions of genotypes and allelic frequencies of the polymorphisms of the PAI-1 promoter gene have been presented in Tables 2 and 3, respectively. Accordingly, the prevalence of the $4 \mathrm{G} / 4 \mathrm{G}$ genotype was significantly higher in the case group compared to the controls. A significant difference was also found between the two groups regarding the frequency of the $4 \mathrm{G}$ allele.

In order to assess the relationship between PAI-I polymorphisms and CAD progression, linear regression analysis models were employed. The results of the analysis for the $4 \mathrm{G}$ allele $(4 \mathrm{G} / 4 \mathrm{G}, 4 \mathrm{G} / 5 \mathrm{G}$, and $5 \mathrm{G} / 5 \mathrm{G})$ revealed that the unadjusted Odds Ratio (OR) was 2.351 (95\% CI: 3.12 35.31, $\mathrm{P}<0.001)$ for $4 \mathrm{G} / 4 \mathrm{G}$ and 0.69 (95\% CI: $0.61-6.49$, $\mathrm{P}=0.249$ ) for $4 \mathrm{G} / 5 \mathrm{G}$.

The associations between PAI-1 promoter gene polymorphisms and serpin E1 lipid profiles, MDA, and hsCRP levels The plasma level of serpin E1 was significantly higher in the case group carrying the $4 \mathrm{G}$ allele compared

\begin{tabular}{|c|c|c|c|c|}
\hline Variable & & Control $(n=44)$ & Case $(n=46)$ & $P$ value \\
\hline Age, Years & & $60.54 \pm 5.29$ & $62.00 \pm 9.62$ & $0.375^{\mathrm{a}}$ \\
\hline \multirow{2}{*}{ Sex } & Male (n, \%) & $29,65.9$ & $33,71.7$ & \multirow{2}{*}{$0.356^{\mathrm{b}}$} \\
\hline & Female (n, \%) & $15,34.1$ & $13,28.3$ & \\
\hline \multirow[t]{2}{*}{ DM } & Positive (n, \%) & $4,9.1$ & $11,23.9$ & \multirow[t]{2}{*}{$0.053^{\mathrm{b}}$} \\
\hline & Negative (n, \%) & $40,90.9$ & $3,76.10$ & \\
\hline \multirow[t]{2}{*}{ Smoking } & Positive (n, \%) & $10,22.7$ & $23,51.1$ & \multirow[t]{2}{*}{$0.007^{\mathrm{b}}$} \\
\hline & Negative (n, \%) & $34,77.3$ & $23,49.9$ & \\
\hline \multirow[t]{2}{*}{ Hypertension } & Positive (n, \%) & $17,38.6$ & $31,67.4$ & \multirow[t]{2}{*}{$0.007^{\mathrm{b}}$} \\
\hline & Negative (n, \%) & $27,61.4$ & $15,32.6$ & \\
\hline MDA & & $4.80 \pm 0.78$ & $6.10 \pm 1.16$ & $<0.001^{\mathrm{a}}$ \\
\hline Hs-CRP & & $2.61 \pm 1.64$ & $5.33 \pm 2.02$ & $<0.001^{\mathrm{a}}$ \\
\hline Cholesterol (mg/dL) & & $155.7 \pm 25.7$ & $195.2 \pm 48.15$ & $<0.001^{\mathrm{a}}$ \\
\hline Triglyceride (mg/dL) & & $137.4 \pm 43.44$ & $198.4 \pm 57.9$ & $<0.001^{\mathrm{a}}$ \\
\hline HDL (mg/dL) & & $36.75 \pm 4.09$ & $32.04 \pm 3.76$ & $<0.001^{\mathrm{a}}$ \\
\hline LDL (mg/dL) & & $105.6 \pm 40.7$ & $129.3 \pm 34.01$ & $<0.001^{\mathrm{a}}$ \\
\hline PAI-1 (ng/mL) & & $48.19 \pm 12.32$ & $84.34 \pm 9.78$ & $<0.001^{\mathrm{a}}$ \\
\hline Blood sugar (mg/dL) & & $98.27 \pm 31.71$ & $140.1 \pm 75.55$ & $<0.001^{\mathrm{a}}$ \\
\hline
\end{tabular}

Abbreviations: DM, diabetic mellitus

${ }^{*} \mathrm{P}$ value based on ANOVA; ${ }^{* *} \mathrm{P}$ value based on chi-square test

\begin{tabular}{|c|c|c|c|c|}
\hline \multirow{2}{*}{ Groups } & \multicolumn{3}{|c|}{ Polymorphism } & \multirow[t]{2}{*}{ P value } \\
\hline & $4 \mathrm{G} / 4 \mathrm{G}$ & $4 \mathrm{G} / 5 \mathrm{G}$ & $5 \mathrm{G} / 5 \mathrm{G}$ & \\
\hline \multirow{2}{*}{ Control } & 8 & 18 & 18 & \multirow{4}{*}{$<0.001$} \\
\hline & $18.18 \%$ & $40.91 \%$ & $40.91 \%$ & \\
\hline \multirow{2}{*}{ Case } & 28 & 12 & 6 & \\
\hline & $60.87 \%$ & $26.09 \%$ & $13.04 \%$ & \\
\hline
\end{tabular}

${ }^{*} \mathrm{P}$ value based on chi-square test

\begin{tabular}{ll}
\hline Table 3. Allelic Frequencies of PAI-1 Promoter Gene \\
\hline Allele & Allele Frequency $(\mathbf{n}=\mathbf{1 8 0})$ \\
\hline $\mathbf{4 G}(\mathbf{n}, \%)$ & $102(57)$ \\
$\mathbf{5 G}(\mathbf{n}, \%)$ & $78(43)$ \\
\hline
\end{tabular}

Abbreviations: DM, diabetic mellitus

${ }^{*} \mathrm{P}$ value based on ANOVA; ${ }^{* *} \mathrm{P}$ value based on chi-square test 
to those homozygous for the $5 \mathrm{G}$ allele $[4 \mathrm{G} / 4 \mathrm{G}(87.85 \pm$ $9.21)$ vs. $4 \mathrm{G} / 5 \mathrm{G}(80.17 \pm 8.81), \mathrm{ng} / \mathrm{mL}, \mathrm{P}=0.041 ; 4 \mathrm{G} / 4 \mathrm{G}$ $(87.85 \pm 9.21)$ vs. $5 \mathrm{G} / 5 \mathrm{G}(76.33 \pm 6.65), \mathrm{mg} / \mathrm{dL}, \mathrm{P}=0.016]$. Additionally, a significant difference was observed among the three genotypes in the CAD group with regard to plasma HDL levels [4G/4G (29.89 \pm 2.65$)$ vs. 4G/5G (35.50 \pm 2.77$)$, $\mathrm{mg} / \mathrm{dl}, \mathrm{P}<0.001 ; 4 \mathrm{G} / 4 \mathrm{G}(29.89 \pm 2.65)$ vs. 5G/5G (35.16 \pm 2.48), $\mathrm{mg} / \mathrm{dL}, \mathrm{P}<0.001]$. Also, significant differences were observed among the three genotypes in the control group regarding LDL and cholesterol levels [LDL: 4G/4G (132.1 \pm 31.9) vs. $5 \mathrm{G} / 5 \mathrm{G}(89.2 \pm 35.3), \mathrm{mg} / \mathrm{dL}, \mathrm{P}=0.031$; cholesterol: 4G/4G (180.3 \pm 19.1$)$ vs. $5 \mathrm{G} / 5 \mathrm{G}(147.6 \pm 23.1), \mathrm{mg} / \mathrm{dL}, \mathrm{P}$ $=0.006)$. However, no other significant differences were detected among the three PAI-1 genotypes with respect to the measured parameters.

\section{Discussion}

Studies have shown that CAD has a significant genetic basis in individuals under the age of 75 years (11). Indeed, several studies have made efforts to show the genetic factors involved in predisposition to CAD. Identification of these factors improves our knowledge about the pathophysiology of CAD, eventually playing a critical role in directing preventative and therapeutic efforts (10). Generally, a reduction in plasma fibrinolytic activity has been observed in patients with different stages of CAD and it has been suggested that genetic variability may be responsible for this phenomenon. Reduction of fibrinolytic potential is commonly related to increased plasma levels of serpin E1. Elevated serpin E1 concentrations in turn predict subsequent myocardial infarction instable angina pectoris and are associated with progressive CAD in young men with a history of myocardial infarction (12).

The present study findings indicated a remarkable association between $4 \mathrm{G} / 5 \mathrm{G}$ promoter polymorphism of the PAI-1 gene and risk of CAD. Our findings and those of many meta-analyses have also demonstrated a direct connection between this polymorphism and severity of CAD $(13,14)$. The results of our study showed that PAI-1 was significantly elevated in the CAD patients in comparison to the controls and was significantly associated with severity of the disease.

Our study results also revealed that the plasma level of serpin E1 was significantly higher in the 4G/4G genotype compared to the $4 \mathrm{G} / 5 \mathrm{G}$ and $5 \mathrm{G} / 5 \mathrm{G}$ genotypes in the case group. This was consistent with the results of the studies conducted by T. Hokestra et al. (15) and JG Van Derbom et al. (16). In general, both alleles (4G/4G and 5G/5G) bind a transcriptional factor, but only $5 \mathrm{G} / 5 \mathrm{G}$ binds a repressor protein (17). This implies that PAI-1 transcription is increased in the presence of $4 \mathrm{G} / 4 \mathrm{G}$ polymorphism. In the same line, several researches have indicated that $4 \mathrm{G} / 4 \mathrm{G}$ polymorphism of PAI-1 carried by many Caucasian and Asian populations affected the plasma levels of serpin E1, and high levels of serpin E1 were associated with several components of the atherothrombotic process, including endothelial cell, Smooth Muscle Cell (SMC), and platelets (18-20). PAI-1 reduced SMC content of the developing atherosclerotic plaque. Furthermore, production of collagen and other extracellular matrix proteins decreased in plaques. In this situation, plaques are prone to rupture and this mechanism is a potential explanation for the increased risk of myocardial infarction and CAD associated with overexpression of serpin E1 (21).

Considering the lipid profile, PAI-1 was positively associated with cholesterol, triglyceride, and LDL, but negatively associated with HDL. Nonetheless, the molecular mechanism of this association is not clear. The $4 \mathrm{G}$ allele is known to be associated with a higher PAI-1 antigen level, which is in turn correlated to lipid profiles. This inverse association between PAI-1 promoter gene polymorphism and lipid profile has already been described by Chen et al. (22) and I Juhan-Vague et al. (23). This association is influenced by the genotype in the region of the PAI1 promoter gene (24). In the present study, the subject with $4 \mathrm{G} / 4 \mathrm{G}$ polymorphism in the CAD group had higher cholesterol and LDL levels and lower HDL levels compared to other genotypes. Moreover, serum cholesterol and LDL levels were higher in the control subjects with $4 \mathrm{G} / 4 \mathrm{G}$ polymorphism, whereas lower HDL levels were observed in the case subjects with $4 \mathrm{G} / 4 \mathrm{G}$ polymorphism. This may be related to consumption of lipid lowering drugs, such as gemfibrozil and statins, by the CAD subjects. Lipid lowering drugs may not only reduce cholesterol and triglyceride levels, but can also decrease serpin E1 plasma levels and PAI-1 mRNA expression (25). The PAI1 mRNA concentration and secretion rate appears to be high in subcutaneous adipose tissue (26). Clinical studies have shown that significant weight loss reduced plasma serpin E1 levels in obese humans $(27,28)$. Generally, obesity is an important component of the Insulin Resistance Syndrome (IRS). Combined effect of insulin-dependent mechanism and adipose tissue might have a stronger influence on serpin E1 plasma levels (29). Furthermore, a large body of literature demonstrated that free radicals have been entangled in cardiac ischemic injury. These free radicals are produced in the body by reduction of oxygen. In normal conditions, they are removed by different antioxidative defense systems present in blood and tissues. In case of myocardial ischemia, which can lead to myocardial infarction, excessive free radicals may be generated (30), and measurement of MDA is a good marker of radical stress during reperfusion of the ischemic myocardium (31). To evaluate the oxidative stress status in the CAD patients in the current study, MDA level was assessed and the results showed significantly increased concentrations of MDA, as an index of lipid peroxidation, in the CAD patients compared to the controls, which was correlated to development of the disease. However, no significant association was found between PAI-1 gene polymorphism and serum level of MDA and risk of CAD. Evidence has indicated that inflammation played an important role in development of CAD. Previous studies also suggested that inflammation was not only an important trigger mechanism of coronary syndrome related to plaque rupture, but also participated in atherosclerosis promotion directly and actively $(32,33)$. Moreover, researches have disclosed that hs-CRP was a sensitive systemic marker of inflammation and a potent predictive marker of future cardiovascular risk $(31,34)$. In our study, a significant difference was observed between the patients and the controls regarding the value of 
hs-CRP. Besides, there was an association between hs-CRP and CAD. hs-CRP was also correlated to lipids profile. This finding suggested a relationship between hs-CRP and LDLcholesterol level and metabolic syndrome. Many studies have shown that change in the concentration of plasma lipids in CAD patients definitely contributed to development of vascular disease $(7,31,35)$. In the present study, however, no significant association was found between PAI-1 gene polymorphism, and serum level of hs-CRP and risk of CAD.

\subsection{Study Limitations}

One of the main limitations of the present study was its small sample size. Additionally, other factors might have affected the development of cardiovascular disease. Thus, further studies with larger sample sizes are recommended to be conducted to evaluate the effect of this polymorphism on other risk factors of cardiovascular disease, such as plasminogen and oxidase-LDL.

\subsection{Conclusion}

Our findings suggested that the $4 \mathrm{G} / 5 \mathrm{G}$ polymorphism of the PAI-1 gene was a useful marker of fibrinolytic activity, which might contribute to defective fibrinolytic activity due to elevated serpin E1 plasma level and, consequently, increase the risk of CAD. The results also demonstrated that this genetic variation might be important in association with some other factors, such as increased or decreased triglyceride, cholesterol, LDL, and HDL levels. However, no significant correlation was observed between the serum levels of stress oxidative factors, such as MDA and hsCRP, and PAI-1 4G/5G gene polymorphism. The precise mechanisms of the inter-relationship between oxidative stress and fibrinolysis is not known yet and requires future in-depth studies.

Conflicts of interest: None declared.

\section{Acknowledgements}

This article was a part of a thesis (No. 92/2-4/8) submitted for Master's degree to Faculty of Medicine, Tabriz University of Medical Sciences, Tabriz, Iran.

\section{Authors' Contribution}

Ansar Karimian and Fatemeh Khaki Khatibi developed the original idea and the protocol, Anrsar Karimian wrote the manuscript, Safar Farajnia and Ansar Karimian contributed to development of the PCR-RFLP protocol, and Morteza Ghojazadeh did the final analysis of the data.

\section{Financial disclosure}

We have no financial interests related to the material in the manuscript.

\section{Funding/Support}

This study was supported in part by a grant from the Drug Applied Research Center, Tabriz University of Medical Sciences, Tabriz, Iran.

\section{References}

1. Taylor F, Huffman MD, Macedo AF, Moore TH, Burke M, Davey Smith G, et al. Statins for the primary prevention of cardiovascular disease. Cochrane Database Syst Rev. 2013;1:CD004816.

2. Anderson JL, Muhlestein JB, Habashi J, Carlquist JF, Bair TL, Elmer SP, et al. Lack of association of a common polymorphism of the plasminogen activator inhibitor-1 gene with coronary artery disease and myocardial infarction. J Am Coll Cardiol. 1999;34(6):1778-83.

3. Bozbas H, Yildirir A, Kucuk MA, Ozgul A, Atar I, Sezgin A, et al. Prevalence of coronary artery disease in patients undergoing valvular operation due to rheumatic involvement. Anadolu Kardiyol Derg. 2004;4(3):223-6.

4. Tsantes AE, Nikolopoulos GK, Bagos PG, Bonovas S, Kopterides $\mathrm{P}$, Vaiopoulos $\mathrm{G}$. The effect of the plasminogen activator inhibitor-1 4G/5G polymorphism on the thrombotic risk. Thromb Res. 2008;122(6):736-42.

5. Ossei-Gerning N, Mansfield MW, Stickland MH, Wilson IJ, Grant PJ. Plasminogen activator inhibitor-1 promoter $4 \mathrm{G} / 5 \mathrm{G}$ genotype and plasma levels in relation to a history of myocardial infarction in patients characterized by coronary angiography. Arterioscler Thromb Vasc Biol. 1997;17(1):33-7.

6. Karakurt Ariturk O, Ureten K, Sari M, Yazihan N, Ermis E, Erguder I. Relationship of paraoxonase-1, malondialdehyde and mean platelet volume with markers of atherosclerosis in familial Mediterranean fever: an observational study. Anadolu Kardiyol Derg. 2013;13(4):357-62.

7. Khaki-Khatibi F, Yaghoubi A, Rahbani N. Study of antioxidant enzymes, lipid peroxidation, lipid profile and immunologic factor in coronary artery disease in East Azarbijan. International Journal of Medicine and Biomedical Research. 2013;1(2):147-52.

8. Ridker PM, Danielson E, Fonseca FA, Genest J, Gotto AM, Jr., Kastelein JJ, et al. Rosuvastatin to prevent vascular events in men and women with elevated C-reactive protein. $N$ Engl J Med. 2008;359(21):2195-207.

9. Draper HH, Hadley M. Malondialdehyde determination as index of lipid peroxidation. Methods Enzymol. 1990;186:421-31.

10. Friedewald WT, Levy RI, Fredrickson DS. Estimation of the concentration of low-density lipoprotein cholesterol in plasma, without use of the preparative ultracentrifuge. Clin Chem. 1972;18(6):499-502.

11. Marenberg ME, Risch N, Berkman LF, Floderus B, de Faire U, Genetic susceptibility to death from coronary heart disease in a study of twins. N Engl J Med. 1994;330(15):1041-6.

12. Anvari A, Schuster E, Gottsauner-Wolf M, Wojta J, Huber K. PAI-I $4 \mathrm{G} / 5 \mathrm{G}$ polymorphism and sudden cardiac death in patients with coronary artery disease. Thromb Res. 2001;103(2):103-7.

13. Li YY. Plasminogen activator inhibitor- $14 \mathrm{G} / 5 \mathrm{G}$ gene polymorphism and coronary artery disease in the Chinese Han population: a metaanalysis. PLoS One. 2012;7(4):e33511.

14. Zhang H, Dong P, Yang X, Liu Z. Plasminogen activator inhibitor-1 $4 \mathrm{G} / 5 \mathrm{G}$ polymorphism is associated with coronary artery disease risk: a meta-analysis. Int J Clin Exp Med. 2014;7(10):3777-88.

15. Hoekstra T, Geleijnse JM, Schouten EG, Kluft C. Diurnal variation in PAI-1 activity predominantly confined to the 4G-allele of the PAI-1 gene. Thromb Haemost. 2002;88(5):794-8.

16. van der Bom JG, Bots ML, Haverkate F, Kluft C, Grobbee DE. The 4G5G polymorphism in the gene for PAI-1 and the circadian oscillation of plasma PAI-1. Blood. 2003;101(5):1841-4.

17. Eriksson P, Kallin B, van 't Hooft FM, Bavenholm P, Hamsten A. Allele-specific increase in basal transcription of the plasminogenactivator inhibitor 1 gene is associated with myocardial infarction. Proc Natl Acad Sci US A. 1995;92(6):1851-5.

18. Mikkelsson J, Perola M, Wartiovaara U, Peltonen L, Palotie A, Penttila A, et al. Plasminogen activator inhibitor-1 (PAI-1) 4G/5G polymorphism, coronary thrombosis, and myocardial infarction in middle-aged Finnish men who died suddenly. Thromb Haemost. 2000;84(1):78-82.

19. Onalan O, Balta G, Oto A, Kabakci G, Tokgozoglu L, Aytemir K, et al. Plasminogen activator inhibitor-1 4G4G genotype is associated with myocardial infarction but not with stable coronary artery disease. J Thromb Thrombolysis. 2008;26(3):211-7.

20. Zhu Y, Carmeliet P, Fay WP. Plasminogen activator inhibitor-1 is a major determinant of arterial thrombolysis resistance. Circulation. 1999;99(23):3050-5.

21. Sobel BE. Increased plasminogen activator inhibitor-1 and vasculopathy $\mathrm{A}$ reconcilable paradox. Circulation. 1999;99(19):2496-8.

22. Chen CH, Eng HL, Chang CJ, Tsai TT, Lai ML, Chen HY, et 
al. $4 \mathrm{G} / 5 \mathrm{G}$ promoter polymorphism of plasminogen activator inhibitor-1, lipid profiles, and ischemic stroke. J Lab Clin Med. 2003;142(2):100-5.

23. Juhan-Vague I, Pyke SD, Alessi MC, Jespersen J, Haverkate F, Thompson SG. Fibrinolytic factors and the risk of myocardial infarction or sudden death in patients with angina pectoris. ECAT Study Group. European Concerted Action on Thrombosis and Disabilities. Circulation. 1996;94(9):2057-63.

24. Song J, Yoon YM, Jung HJ, Hong SH, Park H, Kim JQ. Plasminogen activator inhibitor-1 $4 \mathrm{G} / 5 \mathrm{G}$ promoter polymorphism and coagulation factor VII Arg353--> Gln polymorphism in Korean patients with coronary artery disease. J Korean Med Sci. 2000;15(2):146-52.

25. Huber K, Christ G, Wojta J, Gulba D. Plasminogen activator inhibitor type-1 in cardiovascular disease. Status report 2001. Thromb Res. 2001;103 Suppl 1:S7-19.

26. Alessi MC, Peiretti F, Morange P, Henry M, Nalbone G, JuhanVague I. Production of plasminogen activator inhibitor 1 by human adipose tissue: possible link between visceral fat accumulation and vascular disease. Diabetes. 1997;46(5):860-7.

27. Juhan-Vague I, Alessi MC. PAI-1, obesity, insulin resistance and risk of cardiovascular events. Thromb Haemost. 1997;78(1):656-60.

28. Kockx M, Leenen R, Seidell J, Princen HM, Kooistra T. Relationship between visceral fat and PAI-1 in overweight men and women before and after weight loss. Thromb Haemost. 1999;82(5):1490-6.
29. Loskutoff DJ, Samad F. The adipocyte and hemostatic balance in obesity: studies of PAI-1. Arterioscler Thromb Vasc Biol. 1998;18(1):1-6.

30. Stoop AA, Lupu F, Pannekoek H. Colocalization of thrombin, PAI-1, and vitronectin in the atherosclerotic vessel wall: A potential regulatory mechanism of thrombin activity by PAI-1/vitronectin complexes. Arterioscler Thromb Vasc Biol. 2000;20(4):1143-9.

31. Sharma SB, Garg S, Veerwal A, Dwivedi S. hs-CRP and oxidative stress in young CAD patients: A pilot study. Indian J Clin Biochem. 2008;23(4):334-6.

32. Arroyo-Espliguero R, Avanzas P, Cosin-Sales J, Aldama G, Pizzi C, Kaski JC. C-reactive protein elevation and disease activity in patients with coronary artery disease. Eur Heart J. 2004;25(5):401-8.

33. Ghodke SS, Padalkar RK, Bhagat SS, Ghone RA, Patil SM. hs-CRP: A "Golden Marker" of inflammation and coronary artery disease. IJHSR. 2012;2(6):42-6.

34. Thakur S, Gupta S, Parchwani H, Shah V, Yadav V. Hs-CRP-A potential marker for coronary heart disease. Indian Journal of Fundamental and Applied Life Sciences. 2011;1(1):1-4.

35. Mutlu-Turkoglu U, Akalin Z, Ilhan E, Yilmaz E, Bilge A, Nisanci Y, et al. Increased plasma malondialdehyde and protein carbonyl levels and lymphocyte DNA damage in patients with angiographically defined coronary artery disease. Clin Biochem. 2005;38(12):1059-65. 